Check for updates

Portsmouth

Cite this as: $B M J$ 2021;375:n2845 http://dx.doi.org/10.1136/bmi.n2845 Published: 18 November 2021

\title{
Covid-19: Antimicrobial misuse in Americas sees drug resistant infections surge, says WHO
}

Luke Taylor

The use of antimicrobials against covid-19 is driving a surge in drug resistant infections in the Americas, WHO's Americas' branch, the Pan American Health Organization (PAHO), has said.

Drugs such as azithromycin, chloroquine, and ivermectin have been shown to be ineffective against covid-19 in clinical trials but were widely prescribed by doctors and self administered by the public as the region was devastated by the coronavirus pandemic, PAHO said. ${ }^{1}$

Latin American nations such as Argentina, Ecuador, Guatemala, Paraguay, and Uruguay have reported increases in drug resistant infections, and a recent PAHO Epidemiological Alert showed a spike in the emergence of bacteria resistant to antimicrobials across the region.

"We've seen the use of antimicrobials rise at unprecedented levels, with potentially serious consequences for years to come," PAHO director Carissa Etienne told journalists at a press briefing on 17 November.

Sales of drugs such as the antiparasitic ivermectin have spiked in the Americas during the pandemic as the dire public health situation made many people desperate for a miracle cure and presidents sowed hope by talking them up. ${ }^{2}$ The Americas is the region of the world worst affected by covid-19, having reported nearly half of the world's deaths despite being home to around an eighth of its population. ${ }^{3}$

As well as the use of unproved drugs to treat covid-19, the prescription of antimicrobials to patients who did not need them was likely to be causing an increase in drug resistant infections, PAHO said. More than $90 \%$ of patients admitted to hospital for covid-19 in the Americas were prescribed an antimicrobial, but only $7 \%$ needed them to treat a secondary infection.

"Thanks to the overuse and misuse of antibiotics and other antimicrobials, we risk losing the drugs we rely on to treat common infections," said Etienne.

The growing resistance to antibiotics, antivirals, antifungals and antiparasitics is one of the world's top 10 public health threats, says WHO, with growing resistance to antibiotics a particular concern. ${ }^{4}$ Antibiotic resistant infections such as gonorrhoea, pneumonia, salmonella, and tuberculosis are becoming more common and difficult to treat.

“Countries must promote clear, evidence based treatment guidelines so clinicians know when these drugs are recommended," Etienne said. This includes clear national guidelines for when doctors should prescribe antimicrobials and ensuring that people cannot buy them over the counter without a prescription. New antimicrobials must also be developed as the world is reliant on a few treatments for a plethora of infections.

Increases in drug resistant infections have been reported outside the Americas, including the UK, where Susan Hopkins, chief medical adviser at the UK Health Security Agency said on 17 November it was a "hidden pandemic."5

The overcrowding of hospitals and lack of PPE are likely to have contributed to the growing ability of infections to fight off treatments in the Americas, PAHO said.

The region seems to be at an inflection point in the pandemic, with more than half of people in Latin America and the Caribbean now fully vaccinated against SARS-CoV-2. Those countries recorded a 5\% decrease in new infections last week and a $17 \%$ decrease in deaths, though Etienne warned against complacency, as behaviour during the upcoming holiday season encourages virus transmission.

Pan American Health Organisation. Americas report surge in drug-resistant infections due to misuse of antimicrobials during pandemic. https://www.paho.org/en/news/17-11-2021-americas-report-surge-drugresistant-infections-due-misuse-antimicrobials-during.

2 Demand surges for deworming drug for covid, despite scant evidence it works. New York Times. https://www.nytimes.com/2021/08/30/health/covid-ivermectin-prescriptions.html.

3 World Health Organization. WHO coronavirus (covid-19) dashboard. https://covid19.who.int.

4 World Health Organization. Antimicrobial resistance. https://www.who.int/news-room/fact-sheets/detail/antimicrobial-resistance. UK Health Security Agency. Antibiotic-resistant infections fell in 2020 for first time since 2016, but UKHSA warns drop likely temporary. https://www.gov.uk/government/news/antibiotic-resistant-infections-fellin-2020-for-first-time-since-2016-but-ukhsa-warns-drop-likely-temporary.

This article is made freely available for use in accordance with BMJ's website terms and conditions for the duration of the covid-19 pandemic or until otherwise determined by BM]. You may use, download and print the article for any lawful, non-commercial purpose (including text and data mining) provided that all copyright notices and trade marks are retained. 